\title{
Mini Review of the Cost-Effectiveness of Unilateral Osseointegrated Implants in Adults: Possibly Cost-Effective for the Correct Indication
}

\author{
Matthew G. Crowson Debara L. Tucci \\ Division of Otolaryngology - Head and Neck Surgery, Duke University Medical Center, Durham, N.C., USA
}

\section{Key Words}

Bone-anchored hearing aid - Osseointegrated implant .

Cost-effectiveness $\cdot$ Hearing aids $\cdot$ Hearing rehabilitation

\begin{abstract}
An osseointegrated implant (e.g. bone-anchored hearing aid, BAHA) is a surgically implantable device for unilateral sensorineural and unilateral or bilateral conductive hearing loss in patients who otherwise cannot use or do not prefer a conventional air conduction hearing aid (ACHA). The specific indications for an osseointegrated implant are evolving and dependent upon the country or regulatory body overseeing the provision of these devices. However, there are general groups of patients who would be likely to benefit, one such group being patients with congenital aural atresia. Given the anatomical aberrancies with aural atresia, these subjects cannot wear ACHAs. Another group of patients who may benefit from an osseointegrated implant over an ACHA are patients with chronically draining otological infections. As the provision of an osseointegrated implant requires a surgical procedure, there are inherent direct and indirect costs associated with its use beyond those required for an ACHA. Consideration of outcomes and cost-effectiveness for the osseointegrated implant versus the ACHA is prudent pri-
\end{abstract}

or to making policy decisions in a setting of limited health care resources. We performed a mini review on all available cost-effectiveness analyses of osseointegrated implants published in Medline. There are only 2 contemporary costeffectiveness analyses published to date. There is limited quality of life data available for patients living with an osseointegrated implant. As a result, the cost-effectiveness of the osseointegrated implant, specifically the BAHA, compared to conventional hearing aid devices remains unclear. However, there are clear indications for the BAHA when a standard hearing aid cannot be used (e.g. chronic draining ear) or in single-sided severe-to-profound hearing loss with reasonable hearing in the contralateral ear. The BAHA should not be considered interchangeable with the ACHA with regard to cost-effectiveness, but rather considered as an effective option for the patient for the correct indication.

(c) 2016 S. Karger AG, Basel

\section{Introduction}

An osseointegrated implant (e.g. bone-anchored hearing aid, BAHA) is a surgically implantable device for unilateral sensorineural and unilateral or bilateral conductive hearing loss in patients who otherwise cannot use or

\section{KARGER}

E-Mail karger@karger.com

www.karger.com/aud (c) 2016 S. Karger AG, Base

1420-3030/16/0212-0069\$39.50/0
Matthew G. Crowson, MD

Division of Otolaryngology - Head and Neck Surgery

Duke University Medical Center

200 Trent Drive, Durham, NC 27710 (USA)

E-Mail matthew.crowson@duke.edu 
do not prefer a conventional air conduction hearing aid (ACHA). The three main components of the device are: (1) an implant that is anchored in the temporal bone, (2) an abutment and (3) a removable sound processor that converts auditory input into vibrotactile stimuli. An osseointegrated implant is surgically implanted in either a one- or two-stage procedure in an ambulatory setting. As the provision of an osseointegrated implant requires a surgical procedure, there are inherent direct and indirect costs associated with its use beyond those required for an ACHA. The Centers for Medicare and Medicaid Services has recently proposed to withdraw coverage for the osseointegrated implant [Alissa, 2014]. Consideration of outcomes and cost-effectiveness for the osseointegrated implant versus the ACHA is prudent prior to making policy decisions in a setting of limited health care resources.

\section{Literature Review}

Cost-effectiveness research seeks to quantitatively characterize the costs and effectiveness of medical therapies and interventions. Measures of efficacy specific to diseases and conditions exist, but investigators of costeffectiveness have sought to convey efficacy through 'quality-adjusted life years' (QALY) or 'disability-adjusted life years' as a universal language for efficacy. To compare the results of cost-effectiveness studies to one another, it is useful to generate a common ratio from which direct comparisons can be drawn. One such ratio is the incremental cost-effectiveness ratio (ICER). The numerator of the ratio is the difference in total costs between the 'new' therapy being tested and the established standard of care. The denominator is the difference in the health effects (e.g. QALY) between the two therapies evaluated. With this ratio, cost-effectiveness analyses for different therapies and disease areas can be directly compared to make health care policy and resource utilization decisions. While there is no universally accepted ICER value for adopting new therapies, the National Institute for Health and Clinical Excellence (NICE) states that an ICER of below GBP 30,000 (USD 45,000) per QALY gained is cost-effective [Devlin and Parkin, 2004].

Monksfield et al. [2011] sought to establish a formal cost-effectiveness analysis for the BAHA osseointegrated implant via a prospective case-control study in 70 patients undergoing their first BAHA. The outcome measures included QALY gain and an ICER ratio. The total costs for the BAHA were derived from initial evaluation, surgery, ongoing annual evaluation and maintenance, and an upgrade after 5 years to the newest model for an estimated life expectancy of the individual patient. A mean QALY gain was derived from results of questionnaire responses using the Health Utilities Index (HUI) questionnaire in conjunction with life expectancy estimations. The HUI questionnaire accounts for hearing as one of the dimensions generating a health utility score, which is used to calculate the QALY. Conventional hearing aid costs were estimated from the cost of providing a hearing aid with a replacement cost every 5 years, assuming hearing aid use would continue at the same level throughout life. The total cost of the BAHA in the first year was estimated to be a mean GBP 5,689 (USD 9,240), with GBP 1,004 (USD 1,630) annually thereafter, with a total estimated cost of GBP 21,430 (USD 34,681) over the life expectancy of the patient. A replacement processor every 5 years was included at a cost of GBP 260 (USD 417). Conventional hearing aid total costs over the same time interval were estimated at GBP 827 (USD 1,241). Compared to conventional ACHA use, the BAHA has a mean ICER of GBP 17,610 (USD 26,415) per QALY gained. The authors concluded that BAHA technology is cost-effective at the thresholds established by NICE. The authors further contend that if the BAHA is partly or fully supported by private insurance, the cost-effectiveness is improved as the cost to provide or maintain the device is transferred to a private third party (table 1 ).

Colquitt et al. [2011] performed a systemic review of 12 contemporary papers to assess the clinical effectiveness and cost-effectiveness of BAHA osseointegrated implant versus conventional hearing aids (ACHA and boneconduction hearing aids, BCHA) for bilateral hearing loss. The authors report that the overall quality of evidence is weak for the studies reviewed and a meta-analysis was impossible due to differences in outcome measures and patient populations. They performed a costeffectiveness analysis with cost and HUI questionnaire data for both adults and children. The total cost for the BAHA procedure in adults was estimated at GBP 2,994 (USD 4,863), GBP 3,308 (USD 5,374) for the processor and maintenance in the first year, and GBP 786 (USD $1,277)$ for annual maintenance thereafter. A replacement processor every 5 years was included at a cost of GBP 260 (USD 417). The total cost over a 10-year time interval was reported to be GBP 15,785 (USD 25,556). The total cost of providing a BCHA was estimated between GBP 289 and 522 (USD 463-837) for the first year, with annual maintenance costs of GBP 50 (USD 80), and a replacement cost of between GBP 232 and 465 (USD 372-746) every 5 years. HUI questionnaire data was used to calcu- 
Table 1. Comparisons of cost inputs and analysis outputs for two studies evaluating the cost-effectiveness of the BAHA osseointegrated implant

\begin{tabular}{|c|c|c|c|c|c|c|c|}
\hline Study & $\begin{array}{l}\text { Procedure cost, } \\
\text { first year }\end{array}$ & $\begin{array}{l}\text { Processor and } \\
\text { maintenance costs, } \\
\text { first year }\end{array}$ & $\begin{array}{l}\text { Total cost, } \\
\text { first year }\end{array}$ & $\begin{array}{l}\text { Annual costs, } \\
\text { after first year }\end{array}$ & Total cost & ICER & Study conclusions \\
\hline $\begin{array}{l}\text { Colquitt et al., } \\
\text { [2011] }\end{array}$ & $\begin{array}{l}\text { GBP 2,994.07 } \\
\text { (USD 4,863) }\end{array}$ & $\begin{array}{l}\text { GBP 3,308 } \\
\text { (USD 5,374) }\end{array}$ & $\begin{array}{l}\text { GBP } 6,618 \\
\text { (USD 10,750) }\end{array}$ & $\begin{array}{l}\text { GBP } 786 \\
\text { (USD 1,277) }\end{array}$ & $\begin{array}{c}\text { GBP } 15,785^{\mathrm{b}} \\
(\mathrm{USD} 25,556)\end{array}$ & $\begin{array}{l}\text { GBP } 46,628 \\
-100,029 \\
\text { (USD 75,491 } \\
-61,949)\end{array}$ & $\begin{array}{l}\text { Unlikely to be a cost-effective } \\
\text { option where the benefits are } \\
\text { similar to non-BAHA } \\
\text { comparators }\end{array}$ \\
\hline
\end{tabular}

a Time interval assumed is calculated life expectancy. ${ }^{\mathrm{b}}$ Time interval assumed is 10 years.

late QALYs. Compared to BCHA, the BAHA has an ICER of GBP 46,628-100,029 (USD 75,491-161,949) per QALY gained and is significantly higher than the NICE cost-effectiveness thresholds. The authors conclude that the BAHA is unlikely to be a cost-effective option compared to other devices when the benefits are similar. The ICER is significantly higher in this systematic review versus the cost-effectiveness analysis of Monksfield et al. [2011] as the authors also factored in costs for 'adverse events' and a smaller computed QALY benefit (table 1). However, Colquitt et al. [2011] contend that their cost-effectiveness and ICER calculations are severely limited by a lack of useable evidence on the quality of life outcomes of BAHA versus conventional aids (table 1 ).

\section{Conclusion}

In an evolving era of health care stewardship, introspection on the value of therapies is prudent to ensure high quality care is delivered to all that need it. Cost-effectiveness analyses are an effective tool for comparing the relative value of therapies, and these comparisons can only be accurate when the quality of the ratio inputs are high. We reviewed a single case-control level 3b study [Monksfield at al., 2011] and a systematic review level 3a study [Colquitt et al., 2011]. There is limited quality of life data available for patients living with an osseointegrated implant. As a result, the cost-effectiveness of the osseointegrated implant, specifically the BAHA, compared to conventional hearing aid devices remains unclear. However, there are clear indications for the BAHA when a standard hearing aid cannot be used (e.g. congenital aural atresia and a chronic draining ear) or in single-sided severe-to-profound hearing loss with reasonable hearing in the contralateral ear. The BAHA should not be considered interchangeable with the ACHA with regard to indication, but rather as an effective option for the patient for the correct indication.

\section{Disclosure Statement}

No funding was received for this study. The authors have no financial or other pertinent conflicts of interest to disclose.

\section{References}

Cost-Effectiveness of Unilateral

Osseointegrated Implants in Adults
Alissa K: Field fights proposal to withdraw osseointegrated implant coverage. Hear J 2014;67: 22-22.

Colquitt JL, et al: Bone-anchored hearing aids (BAHAs) for people who are bilaterally deaf: a systematic review and economic evaluation. Health Technol Assess 2011;15:1-200, iii-iv.
Devlin N, Parkin D: Does NICE have a cost-effectiveness threshold and what other factors influence its decisions? A binary choice analysis. Health Econ 2004;13:437-452.

Monksfield P, et al: Cost-effectiveness analysis of the bone-anchored hearing device. Otol Neurotol 2011;32:1192-1197. 